\title{
Collaborating with other Disciplines: Best Practice For Legal Clinics - A Case Study of the Women's Law Clinic, University of Ibadan Nigeria
}

\author{
Omolade Olomola,* \\ Oluyemisi Bamgbose,
}

\section{Abstract}

There is a gradual shift in research towards a multi-disciplinary approach. This paradigm move is in compliance with globalization. According to Carla Mariano, the human service professions are facing problems so complex that no one discipline can possibly respond to them effectively. ${ }^{1}$ It has been noted that many clients in the Women's Law Clinic (WLC) of the University of Ibadan not only have problems tagged as legal, but problems closely related to other disciplines such as psychology, sociology, medicine, counselling and social works. It was therefore so obvious that the clinic was not an island; it could not exist all alone and effectively find a holistic solution to the all embracing problems presented by the clients. The clinic therefore partnered with other departments/units to achieve its goals.

* Omolade Olomola, Lecturer, Faculty of Law \& Clinician, Women’s Law Clinic University of Ibadan, Nigeria

** Oluyemisi Bamgbose, Professor of Criminal Law and Criminology Dean Faculty of Law and Director Women's Law Clinic, University of Ibadan, Nigeria Collaborating with other Disciplines: Best Practice For Legal Clinics - A Case Study of the Women's Law Clinic, University of Ibadan Nigeria

1 Mariano Carla (1989) The case for interdisciplinary collaboration Nursing Outlook November/December 1989 at www.umdnj.edu/idsweb/idst5340/interdisciplinarycollaboration.pdf Retrieved on I June 2012 
The goals of the WLC include providing legal services to the less advantaged women in society. It is a specialized clinic for women. It started off in the areas of human rights and family law, and has since expanded to accommodate other areas of law.

Thus in the light of the above, this paper considers ways by which legal clinics can collaborate with other disciplines in order to render all-round and balanced services to its clients. It details an interdisciplinary collaboration between the WLC in the Faculty of Law, University of Ibadan, Ibadan and other disciplines and units within and outside the University.

A personal involvement in the problems of the disadvantaged and a solution to the problem can be one of the most rewarding experiences in the life of a lawyer.

Clients in a clinic present different cases expecting the clinician to find a solution to the problems whether or not it is legal. This makes partnering with other disciplines a best practice to meet the expectations of the client.

\section{History of the Women's Law Clinic, Faculty of Law, University of Ibadan}

The idea to start a legal clinic was conceived during a stakeholders' forum held in 2005 at the Premier Hotel, Ibadan, Oyo State, Nigeria. At the forum, representatives from some human rights NGOs lamented the lack of adequate personnel and funding to reach and service the target population. It was noted at that meeting that systematic efforts at protecting the rights of women would require the provision of additional legal services. It was then suggested that creative legal solutions like clinical legal education that enable women to have greater access to legal representation would help to eliminate barriers to access to justice. It was noted that academic institutions would have to collaborate with NGOs and existing governmental legal institutions in addressing these issues in order to make any significant impact.It was also recognized that contribution from the academic community; including the legal education system, could have a significant impact in advancing the response to women's justice issues in Nigeria. University-based activities that include providing legal aid and conducting research would complement and support the exemplary work of NGOs working in this area. It was noted that inadequate research on identifying and understanding issues associated with women's access to justice as well as inadequate information about women's rights NGOs have contributed to women's lack of access to justice. ${ }^{2}$ Such research findings would help to define or understand the issues related to access facing women; evaluate the effectiveness of current programs addressing justice issues for women and design new programs to do the same. ${ }^{3}$

It was therefore agreed at the stakeholders meeting that one of the ways to overcome the problem of access of women to justice, is to establish a legal clinic at the Faculty of Law, University of Ibadan, which would provide free legal services to indigent women while training and engaging the services of law students and staff clinicians. The Faculty of Law agreed to start a specialized clinic to provide pro bono services for indigent women and adopt clinical legal education methods in training the students. The decision of the Faculty stems out of the fact that it is committed to the transformation of the society and particularly to fulfil the mission of the University which is to contribute to the transformation of society through creativity and innovation. ${ }^{4}$

\footnotetext{
2 Ibid

3 Ibid

4 Vision of the University of Ibadan retrieved from http://ww.ui.edu.ng/content/vision-and-mission/ on June 30, 2012
} 
The Vision Statement of the Faculty is to be a World Class Faculty of Law, dedicated to excellent legal training, research and development aimed at meeting the needs of the society; and the Mission Statements of the Faculty are:-

1. To expand the frontiers of legal knowledge through learning and research.

2. To produce law graduates who are worthy in character, learning and sound judgment.

3. To contribute to the transformation of society through legal creativity, research and clinical legal education.

4. To serve as a dynamic custodian of society's legal rights and values and thus sustain its integrity.

5. To be a centre of excellence in research for legal models of cutting edge global issues.

6. To be a focal point and voice for law faculties and legal education in sub Saharan Africa. ${ }^{5}$

The WLC was formally inaugurated on the 18th of July 2007 with good publicity at local and national levels; in print and electronic media.

The Women's Law Clinic was therefore established in 2007 under Consortium for Development Partnerships (CDP) Project on 'The Rule of Law: Access to Justice. The CDP is an international consortium of institutions devoted to conducting collaborative research and capacity- building activities in West Africa. The Faculty of Law, University of Ibadan, Nigeria is one of the CDP member institutions playing an active role in the projects of the consortium. The clinic is one of the eight (8) projects developed and effectively launched.

The Women's Law Clinic, University of Ibadan, Nigeria (WLC) is a specialized law clinic. It is a specialized clinic in the sense that it is for women and it began offering legal services in the areas of human rights and family law, which are in fact very wide areas and has since expanded to accommodate other areas of law. The clinic is a law school based in-house clinic located within the Law Faculty, University of Ibadan, but in a separate building. It is also a live client clinic as students come in contact with live clients. It is also a clinic where students for academic credit and under the supervision of staff supervisors/clinicians, provide pro bono legal services to indigent and less advantaged women within Ibadan metropolis. ${ }^{6}$

The WLC was established under phase I of the project. The clinic started in 2007 with a Director, a full time Clinic Administrator, a clerk, a driver, five male and female staff clinicians and about twenty law student clinicians. As at the 2011/2012 session, the number of staff rose to ten academic staff clinicians, and eighty (80) students both at undergraduate and post graduate levels. The final year undergraduate students of Criminology and Public \& International Law and the 700 level (master's programme) students of comparative family law, comparative criminal law and procedure, human rights and alternative dispute resolution are now involved in the clinic service. ${ }^{7}$

5 Vision of the Faculty of Law, University of Ibadan retrieved from http://law.ui.edu.ng/visionandmission on June 302012

6 BamgboseOluyemisi, OlarindeSmaranda, Akintayo John, EkundayoOsifunke, OlaleyeFolake, OlomolaOmolade, AkinbolaBukola, Adejumo Isaac, Lifu Peter, Byron Ibijoke (2011) "Access To Justice And Human Rights For Women Project Under CDP 11" Final Report On CDP Phase 11 Codesria. Submitted by the Women's Law Clinic, Faculty of Law, University of Ibadan, Ibadan. Nigeria

7 Ibid 
With a generous grant from the Netherlands Ministry of Foreign Affairs in 2007 to the Consortium, the clinic was able to take off. The successful operation of the Clinic under the phase I project, provided the impetus to embark on the objectives under CDP phase II which were to continue to provide free legal services to less privileged (indigent) women in Ibadan and its environs; continue to train law students using the Women's Law Clinic in the practice of law by utilizing techniques of clinical legal education to research and document the basic problems on women's access to justice and to carry out intervention programmes in order to facilitate women's access to justice.

The clinic adopts a multidisciplinary approach in the representation of indigent women: It provides free legal and counselling services; educates women on their rights and follows-up on its cases, encourages alternative dispute resolution mechanisms (besides litigation), that remedy wrongs and at the same time maintain the integrity and harmony of the community.

The clients in the clinic as stated above are indigent women. The clinic provides a legal platform for this category of women, who are poor and who have little or no access to justice as a result of social cultural and political factors. At inception, clients who came to the clinic were those that were financially poor and could not afford the services of a lawyer. However, the clinic came to realize that some women were being denied access to justice because of political factors. These categories of women were deemed to be politically indigent. The clinic therefore took in such clients and extended the services to them. The goal of the clinic is therefore to educate them and give assistance with pro bono legal services.

The student clinicians who work in the clinic are trained to put into practice their theoretical legal knowledge, using clinical legal education. They interact with, and advise live clients under the supervision and guidance of staff clinicians. ${ }^{8}$

\section{A Day in the WLC}

A normal day in the WLC starts at 8.am with the clinic administrator and clerk opening up the clinic and resuming for the day's work. Women walk in as new clients, referral cases or on appointment. A roster which is prepared by the clinic administrator is available at the clinic, showing the staff and student clinicians on duty for the day. Clinicians on duty for the day report at the clinic and in their cubicles. The cubicles are to ensure confidentiality and privacy during discussions. In the case of new clients; it is the duty of the clinic administrator to preliminarily determine if the client is eligible for representation in the clinic. Once this is determined, the case is assigned to a group of student clinicians on duty. A case note is opened for the client and all the necessary details and information are recorded. Clients are usually asked what they want or expect from the clinic before any advice is given. This is to allow the client to express herself while at the same time given proper counselling. The clinic has a policy not to impose advice on a client except where it is involves illegality, crime or life is endangered. This is followed by a detailed investigation of the case by the students under the supervision of a staff supervisor. The investigation may include letter writing to parties in the case inviting them to the clinic, immediate intervention in life threatening cases, visitation to parties involved in the case and referrals if necessary. Depending on the nature of the case, appointments are given to clients to enable further investigations. After the exit of the client, the case is reviewed by the students and supervisor on how to proceed. Where the case involves another party, the party is invited to give his or her

$8 \quad$ Ibid 
in own side of the case. The methods adopted in resolving cases in the clinic are the alternative dispute resolution methods that include mediation and reconciliation. Where these methods fail, and there is need to go to court, if the client agrees, court papers are filed on behalf of the client and the client is represented in court.

\section{The Need for Collaboration in the WLC}

The word 'Collaboration' is derived from the words com and labor which means to work jointly with others or together especially in an intellectual endeavor. ${ }^{9}$

The trend for many centuries has been that of single specialization in the different professions and disciplines. There have been arguments between professionals on which profession is the most important or the profession that was first in time and many other arguments. In an article by Bamgbose, an illustration of one of such arguments was given. ${ }^{10}$ It was between a social worker and a lawyer. Each boasted that his profession was the first in time. Both lay claim to the earlier existence by tracing their profession to the story of creation as contained in the Holy Bible. The first argument was from the social worker who claimed that God is the first social worker and his first activity was social work inclined in that God created light out of darkness to enable all living things that were consequently created to have the opportunity to see clearly and enjoy whatsoever God apportioned to them. Bamgbose further stated that in counter attack to this argument, the lawyer said that the first thing God did was to make a law when he said "let there be light". Not wanting to run in contempt of God's court, the universe obliged God and there was light. ${ }^{11}$ He added that the argument had advanced to other areas such as the consideration whether one profession or discipline is relevant to the other or vice versa. ${ }^{12}$ Professionals generally had always looked at cases before them in isolation and only in relation to their own discipline. The effect is that there is no coordinated approach adopted in solving other related cases arising from cases before them and they have not been able to look at problems holistically. This has sometimes aggravated the problem brought before them as problems are at times interwoven. On the approach to issues in contemporary times, Bloch says that there is a strong appeal these days to approaching just about any topic from a global perspective. ${ }^{13}$ In order to provide socially relevant legal education, there is a need to address it from a global dimension. Bloch therefore states that legal education has a global reach as it is available in one form or the other all over the world. ${ }^{14}$

It is high time law clinicians understood that they are members of a team. As such, the overall interest of the client must be their paramount concern.

9 Merriam-Webster's Dictionary and Thesaurus 2006

10 Bamgbose, Olatokunbo John (2002) Social work and the Law. An unpublished seminar paper presented for during the 2002/2003 session during a Social Work course towards the award of a Masters in Social Work in the Faculty of Education

11 Ibid

12 Ibid

13 BlochFrank (2008) Access to Justice and the Global Clinical Movement retrieved fromhttps://law.wustl.edu/ Journal/28/Blochbookpages.pdf on June 302012

14 Ibid 
Mariano has stated that there are many crises facing society today. ${ }^{15}$ She stated that each of these crises requires a comprehensive approach and necessitates that professionals relate to many client institutional systems and collaborate with many professions. Legal education is becoming more interdisciplinary. Chenault is of the opinion that the historical models of single specialization should not continue. He therefore advocated that there be an attempt to develop an integrated whole rather than a combination of separate professional content areas or field. ${ }^{16}$

Mariano therefore opined that the combination of the expertise in one discipline with another will result in coordinated services and provide a more holistic and integrated approach to addressing issues. ${ }^{17}$

With special reference to the legal profession, the conventional attitude of law professionals has been a problem for many centuries. In order to tackle the challenges posed by the knotty issues facing globalization, lawyers are now joining with other disciplines in problem-solving collaborations. ${ }^{18}$ During discussions with clients, it has been discovered that not all cases are solely legal related matters. Many clients who come to the clinic face complex legal, psychological, social welfare, medical, financial, communal and juvenile related issues. Many of the clients who come to the clinic are poor. Apart from the free legal services provided by the clinic, they are not likely to be able to afford the services of other professionals to whom they may be referred to during or after dealing with the legal issue in the clinic or due to lack of knowledge may be unable to pursue the matter to a logical conclusion. The clinic does not have resources to pay for services rendered for these non legal services. As clinicians face the need to solve clients' legal problems and the myriad of other personal, interpersonal and interdisciplinary problems, the need to develop strategies and tactics, which may involve other disciplines, governmental agencies, and various service providers become inevitable. It therefore became necessary to explore alternative methods of solving issues that may arise while dealing with legal issues without incurring further cost.

Apart from clients that walk in to the clinic, the clinic is also committed to educating women who are denied access or who do not have the knowledge as to how to gain access to justice. The student clinicians go on outreaches to educate women in medical clinics, hospitals, open markets, women groups in churches and mosques.

In order to have a holistic approach to the problem brought to the clinic, an interdisciplinary collaboration with other disciplines, professionals and units had to be adopted.

In many of the family related issues pertaining to custody or maintenance, the State Social Welfare Department has had to be involved. Where the matter has a criminal related issue, the police had to be contacted and the clinic had to follow up on the administrative issues. Health related issues are referred to the university health services where it relates to a staff or student of the university or to the appropriate medical clinic with other clients or the Department of Psychology where it is

15 Mariano Carla (1989) The case for interdisciplinary collaborationNursing Outlook November/December 1989 at www.umdnj.edu/idsweb/idst5340/interdisciplinarycollaboration.pdf Retrieved on I June 2012.

16 Chenault, J.andBurnford F eds. (1978) Future Directions for Human Services. In Human Services ProfessionalEducation: Future Directions, New York, McGraw-Hill Book Co., 1978.

17 Mariano Carla (1989) The case for interdisciplinary collaborationNursing Outlook November/December 1989 at www.umdnj.edu/idsweb/idst5340/interdisciplinarycollaboration.pdf Retrieved on I June 2012.

18 Martha Minow (2003) Public and Private Partnerships: Accounting for the new religion. 116 Harvard Law Review 1229 (2003) 
a psychological issue. The clinic has enjoyed a cordial working relationship with the Nigerian Bar Association (NBA) and the International Federation of Women Lawyers (FIDA). In a few cases where clients need to be represented in court, members of these two associations have volunteered their services pro-bono and assisted the clinic.

With this approach, the clinic has had clients whose legal issue has not only been looked into or solved successfully, but other non legal related problems dealt with. Interdisciplinary work has to a great extent assisted in the training of the law students in solving problems using creative methods while it has also introduced a holistic approach to solving cases in the clinic.

Knowledge is power. All women who walk into the clinic, whether they are eligible or not are attended to. Clients, who are not eligible, are still educated and directed appropriately.

The collaboration model used in the women's law clinic and some case studies will be discussed.

\section{Collaborative models and the wlc model}

The WLC works closely with other departments and units of the University of Ibadan. The experts from these disciplines, and those from other organizations within Ibadan metropolis, work together to enhance services for the clients. In addition to the benefits to the clients, the students' professional education is enriched. Mariano (1989) is an advocate of interdisciplinary collaboration. ${ }^{19}$ She stated this in relation to health issues. She however stated that the concept is poorly understood. This statement is true. Quoting $\mathrm{Scot}^{20}$, Mariano went further to state that the term interdisciplinarity is plagued with misunderstandings about terminology. ${ }^{21}$ She added that terms used interchangeably with the word interdisciplinary include multidisciplinary, transdisciplinary, pluridisciplinary and crossdisciplinary and there are different definitions given to the term. One of the definitions is that "it is the continuous interaction of two or more disciplines organized into a common effort to solve or explore a common problem." 22 The authors of this paper adopt this definition as it best describes the collaborative model used in the WLC as will be discussed below.

From the onset, it should be made clear that the WLC does not operate the clinic within clinic model neither does it adopt the integrated model clinic. The other disciplines, professionals or third persons with which the WLC works, are not based and do not have offices within the WLC. Clients who are seen or recognized to be in need of any other professional care are "referred" to the departments or units concerned while the clinicians handling the case has the responsibility of following up on the case. As mentioned earlier, the clinic does not only deal with clients that come into the clinic. The clinic regularly goes out on outreaches to educate women about their

19 Mariano Carla (1989) The case for interdisciplinary collaboration Nursing Outlook November/December 1989 at www.umdnj.edu/idsweb/idst5340/interdisciplinarycollaboration.pdf Retrieved on I June 2012

20 Scott, R. (1979) Personal and institutional problems encountered in being interdisciplinary. In Interdisciplinarity and HigherEducation. ed. by J. J. Kockelmans. University Park, Pennsylvania State University Press, 1979, p. 307

21 Mariano Carla (1989) The case for interdisciplinary collaboration Nursing Outlook November/December 1989 at www.umdnj.edu/idsweb/idst5340/interdisciplinarycollaboration.pdf Retrieved on I June 2012

22 Mariano Carla (1989) The case for interdisciplinary collaboration Nursing Outlook November/December 1989 at www.umdnj.edu/idsweb/idst5340/interdisciplinarycollaboration.pdf Retrieved on I June 2012

Scott, R.Personal and institutional problems encountered in being interdisciplinary. In Interdisciplinarity and HigherEducation.ed. by J. J. Kockelmans. University Park, Pennsylvania State University Press, 1979, p. 307 
rights and sensitize them about the clinic. These outreaches and sensitization drives are held in various communities, markets, religious houses, hospitals and schools as these places have a higher population of indigent women.

In a study, Gross and Filante stated that merely bringing together the legal discipline with another discipline in the University setting does not guarantee educational enhancement. ${ }^{23}$ The above statement was also echoed by Barry, Dubin and Joy. ${ }^{24}$ While agreeing that interdisciplinary clinical programs offer many valuable skills by means of collaboration, they further stated that bringing professionals together does not ensure that they will function well as a team or make appropriate collaborative decision. The position of the authors of this paper is that though the version of the collaboration between the WLC and other units and disciplines is not based on any specific model, it has worked well for the clinic. The WLC took into consideration certain factors which include administrative, space, logistics and cultural and found this type of collaboration, to be the most appropriate and practical one for the clinic. The cases brought to the WLC differ from one to the other. While some are purely legal, the others vary and are interdisciplinary in nature. Therefore, it is convenient for the WLC to refer clients to other collaborating disciplines where there is an existing formal understanding to collaborate.

The student clinicians in the WLC are final year law students and postgraduate students of law. This is to ensure that the students have a proper understanding of the issues being handled, with more experience and skill to advice. This model is to provide legal expertise to the clients while facilitating other services which the client may need. With this model of collaboration, files of clients are restricted to only law clinicians and the confidentiality of the client and the case is protected.

\section{Community Collaboration}

In Africa in general and Nigeria in particular, there are different cultural practices. One of such is obvious in the selection of communities within which researchers carry out their work. During the course of selecting communities within which to embark on the sensitization drives, the clinicians had to meet with the relevant community leaders for permission to relate with the women in the community. This has to do with the culture. It is a cultural practice in most Nigerian indigenous community (where the indigent women live) that the traditional head of the community must give permission before there is any interaction with residents. In Idi-Omo village, a small rural community in Ibadan, Nigeria, there is an on-going collaboration with the community through a working relationship with the community head. The clinic has access in to the community and a working relationship with the women with the kind cooperation of the traditional leader and the head of the women in the community known as Iyalode. ${ }^{25}$ Through this collaboration, the clinic has been able to intervene and resolve disputes in and for the community, regularly organizing programs for women and there are on-going cases that are being handled for some women who

23 Gross, J. I and Filante, R. W (2005) Developing a law / Business Collaboration through Pace's Securities Arbitration Clinic in Fordham Journal of Corporate and Financial Law volume 11 2005-2006 at http://ssm.com/ abstract $=1032301$ Retrieved on 12 June 2012

24 Barry M.M, Dubin, J.C. and Joy, P. A (2000) Clinical Legal Education for the Millennium: The Third Wave. 7 Clinical Law Review. I. 69-70 2000.

25 Iyalode is the administrative head of all women in any traditional south-western community of Nigeria. She also has some controlling powers on women under her community 
are clients in the clinic.

\section{Department of Psychology}

This is a Department within the University located near the Faculty of Law particularly at the Faculty of Social Sciences. In 2009, after clinicians noted that some clients had psychological issues in addition to the legal problems presented at the clinic, the Director and the clinic administrator visited the Psychology Department and met with the Head of Department and clinicians in the Department. The WLC was informed that the Department has an active clinic and would be willing to handle cases referred from the WLC. The agreement was documented with an understanding that both the WLC and the Department of Psychology will benefit mutually. This collaborative relationship is working well. A client whose case is still on-going in the clinic is closely, monitored in the Department of Psychology. However cases that are completed and or closed in the clinic, but still ongoing in the Department of Psychology are left to the discretion of the department as to what to do to it.

\section{Department of Social Work}

This Department is within the University and located in the Faculty of Education. The WLC has enjoyed a working collaboration with the department. Personnel from the department, posted to the social welfare unit of the University Health Services (Jaja Clinic) attend to clients who are referred to them.

\section{Department of Special Education}

The Department is located in the Faculty of Education with different specialized clinics. Referrals are made from the WLC to their clinics.

\section{Department of Guidance and Counselling}

The Department is within the University and is also located in the Faculty of Education. The department approached the clinic with a request that some of their final year students be allowed to spend about six (6) weeks internship in the clinic offering free counselling to clients. The students are posted to the clinic, and the counselling is done in the clinic. Most of the clients that are counselled are those with domestic violence cases and the children of such families. Case files of the clients are studied and appropriate counselling given.

\section{The University Health Center (Jaja Clinic)}

The University Health Center popularly called Jaja Clinic is the health center of the University of Ibadan and located within the University. Jaja Clinic serves both staff and students of the University and services are offered to students free and staff at a very subsidized rate. The maternal health unit of Jaja Clinic, which is for nursing mothers, is opened to the public at a subsidized rate on Tuesdays. The Jaja Clinic is headed by a Medical Director. The WLC has a collaborative working relationship with Jaja clinic especially with the Maternal Health Unit. Once a month, the WLC addresses the nursing mothers who attend the Maternal Health Unit on reproductive health issues and other right matters. Some of the clients in the clinic got to know about the clinic through this sensitization and educative outreach. In addition to the above, medical cases 
involving staff and students are referred to Jaja Clinic while legal issues arising from medical issues are referred from Jaja clinic to the WLC. These are mainly assault and domestic violence cases.

\section{University of Ibadan, Diamond FM Radio Station}

This is the University owned radio station. The station is located within the University campus from where it transmits within and outside the University covering four states in Nigeria. With this relatively large coverage area and the fact that it is aired in Ibadan, the station serves as a means of sensitizing and educating the target group of indigent women. The program is broadcast in English and the local languages. Through this means some of the clients got to know about the clinic. Programs organized by the clinic are also aired on the station.

\section{The Juvenile/ Family Court}

Though the WLC is a specialized clinic for women, the family court in Ibadan requested collaboration with the clinic. This collaborative relationship has eventually been of mutual benefit to both the court and the clinic. Regarding the benefit to the court, a few cases involving female children relating to their sexual habits have been referred to and handled by the clinic. This was as a result of shortage of social workers in the courts. The clinic handled such cases using the legal clinicians, social workers from the University health services and counsellors from collaborating departments. On its own part, the WLC sought the assistance of the juvenile court in the placement of two children for adoption.

\section{The Oyo State Police Command}

On the inauguration of the WLC in 2007, there was wide publicity. At the ceremony, stakeholders including the police, community leaders, magistrates, journalists and many others indicated that they would support the work at the clinic and some agreed to have a collaborative working relationship with the clinic. The collaborative relationship with the police is one of such. Some of the clients in the clinic have expressed their concerns about the police. Whether the concerns are justified or not is not the crux of this paper.

However, Bamgbose (1997), in an article, that examined the perception of the police by the poor, stated that the poor would not want to have anything to do with the police. The involvement of the WLC in cases requiring the police coming in, has allayed any fears

the clients have. The clinic has enjoyed working with the female divisional police officer in charge of the station, under whose jurisdiction the University falls.

A few case studies highlighting the collaboration of the WLC with other disciplines and units are discussed below.

\section{Case WLC/ CAS/ 077}

The client was a 400 level student in the University who was being sexually harassed by her lecturer. She reported this case at the clinic. While the case was being investigated, it was discovered that the issue had a psychological effect on the client. The client was referred to the Department of Psychology of the University and a psychologist took up this aspect of the case. There was need for evidence of this case which the student produced by tricking her lecturer into her hostel and 
pictures of the lecturer were taken in a compromising situation. The matter was later reported to the students' affairs unit of the University and it became a disciplinary matter. The lecturer after due process was followed was dismissed from the University.

\section{Collaborative Department/Unit: Department of Psychology}

\section{Case WLC/CAS/133}

The client came to the clinic because her husband had deserted her and she wanted him to be responsible for her maintenance and the upkeep of the children. The clinician in charge invited the husband to the clinic but he refused to honour the invitation. The clinicians referred the case to the State Social Welfare Unit. (SSWU). The SSWU invited the husband of the client for a meeting with the WLC and the SSWU. The husband agreed to pay for her maintenance and upkeep of the children. The parties then agreed that the agreed sum was to be deposited monthly in a bank account.

\section{Collaborative Unit: State Social Welfare Unit}

\section{Case WLC/CAS/180}

The client, a young girl of about sixteen years old was alleged to have been sexually assaulted by four (4) young boys. The boys were arrested by the police and taken before a Juvenile Court. They alleged that they did not assault the young lady but were having fun with the consent of the girl. The court while considering the case discovered that all parties were sexually active and exposed to sexual activities. The Juvenile Court referred the young girl to the WLC for counselling. The young girl came to the clinic with her parents. The clinicians in this case had to depart from the normal practice of referral and invited a social worker and a guidance counsellor from the Departments of Social Work and Guidance Counselling. This was because of the peculiar nature of the case which involved an under aged girl. The three (3) experts advised and counselled the client on sex education and also had a talk with the parents who appeared to have neglected the young girl. After sessions of advice and counselling spanning over a few weeks, the young client was sent back to the Juvenile Court with a report. The State Juvenile Court has shortage of social workers which makes comprehensive supervision of young offenders impossible. The collaboration with the clinic has been mutual as cases involving children are also brought to the court from the WLC.

\section{Collaborative Departments/Units: Department of Social Work; Department of Guidance and Counselling; State Juvenile Court}

\section{Case WLC/C.AS/181}

The client, a girl of 16 years old claimed before a Juvenile Court that two boys raped her on her way home. She was discovered by a pastor at the scene and the matter reported to her parents. She was taken to the police station and then taken to the hospital. The two boys denied sexually assaulting her. They claimed that they did not forcefully assault her as she claimed, but that our client was the one who persuaded the boys to "sleep" with her. The boys stated that the girl practically begged them to "sleep" with her. The boys are 12 years of age. The parents of both 
boys are divorcees. The State Juvenile Court after listening to the case referred the young girl and her parents to the WLC. Two clinicians were assigned to the case to counsel the girl and her parents. A social worker and a guidance counsellor from the Departments of Social Work and Guidance Counselling were also invited.It was discovered during the counselling that the girl had some mental challenges and other medical issues. The case could not be referred to the University Health Services as the client was neither a staff nor student of the University. However, the observation of the clinic was in the report sent back to the court and the advice for medical intervention in a government health center.

\section{Collaborative Departments/Units: State Juvenile Court; Department of social work and Department of Guidance and Counselling}

\section{Case WLC/CAS/140}

The client, E, a student of the University, reported in the clinic that she was raped by an acquaintance outside the University campus. E alleged that the incident happened in the house of an influential politician and expressed her fears that it might be impossible to obtain justice. The WLC immediately reported the case at the Campus Security Service (CSS) and E was taken to the University Health Services for medical attention. Being a criminal offence, the CSS referred the case to the police having jurisdiction over the matter. E again expressed her fears about going to the police and the clinicians accompanied her. A female police officer and the clinicians then accompanied E to the scene of the crime. Upon getting to the house, the suspect had escaped. All efforts to reach him thereafter proved abortive. The police kept surveillance on the premises for some time and E was told to contact the police any time she heard from the suspect. E after a few weeks came to the WLC and informed the clinicians that she was no longer interested in pursuing the case and would like to face her studies. She was however counselled to complete her medical treatment.

\section{Collaborativedepartments/ Units: University Health Services (Jaja Clinic); The Police}

\section{Case WLC/CAS/108}

The client, F, came to the clinic to report that her siblings (brothers and sisters) beat her. The reason for the beating was to force her out of their parent's house which F was occupying. F, a University staff member was referred to the University Health Services (Jaja Clinic) for medical attention. Several efforts were made by the WLC to invite F's sibling but this proved abortive. Because of the threat to her life, the matter was referred to the Sango Police Station. The WLC observed that F was psychologically disturbed by this problem. She was referred to the Department of Psychology for further treatment. The police intervened into the family matter with the help of the WLC and the matter was amicably settled. 


\section{Collaborative Departments/Units: University health services (Jaja Clinic); Department of Psychology; The Police}

\section{Case WLC/CAS/039}

The client, G, came to the clinic seeking legal aid for access to her children after her husband deserted her taking the children with him. G's husband was invited to the WLC and an agreement was reached by the parties on having access to the children. The agreement was adhered to until the children refused to go back to their father's house. The husband reported at the police station and $\mathrm{G}$ was arrested. At the police station, the WLC represented G. Both parties were advised and counselled by the police and the clinicians. A concrete arrangement was thereafter made on how $G$ will have access to her children on a regular basis. The husband agreed on an allowance to be sent to $G$ for the upkeep of the baby which was to be left with her.

\section{Collaborative Unit: The Police}

\section{Case WLC/CAS/111}

The initial client, $\mathrm{H}$, now deceased reported to the WLC that she became pregnant to her partner to whom she was not legally married. After her baby died a few months after delivery she continued her relationship with her partner. When she got pregnant again, she alleged that her partner denied the pregnancy and deserted her. She asked the clinic to ensure that her partner took care of her, the pregnancy and the baby after delivery. The partner did not honour the letters of invitation written to him by the WLC. Two months after the case came to the WLC, $\mathrm{H}$ died. The immediate sister to $\mathrm{H}$ referred to as J immediately reported the death to the WLC because the family of $\mathrm{H}$ suspected foul play. J was advised to report to the police. Because of her reluctance to go alone, the clinician accompanied her to the police station and the partner was arrested. After the arrest, his family members from his community came to the WLC, seeking the intervention for his release from the police. This case according to the community members was a community/family issue that should be amicably resolved. The police after due investigation found out that the allegation of foul play was not true and the partner was released to his community/family members. The community/ family of the partner of late $\mathrm{H}$, approached the WLC to intervene in the matter which $\mathrm{J}$ is now pursuing in the WLC. J informed the WLC that she was pursuing the case in the WLC on behalf of her family/community members. Investigation by the clinicians handling the case revealed that this was more than a legal issue and that traditional and cultural issues had to be resolved. It was regarded as a taboo in the community of late $\mathrm{H}, \mathrm{J}$ and the partner, to impregnate a woman without paying the bride price and for her to die with the pregnancy while the bride price remains unpaid. The WLC had a clear understanding of the cultural milieu within which the clinic operated. At this stage, a new clinician who understood the culture of the two parties had to be invited to join in the case. The partner was re-invited to the WLC and he honoured the invitation. To resolve the issue, the WLC advised him to go with the representatives of his community members to apologize to the deceased's community members and this was done. J came back to the WLC to report that the case had been settled and the case file was closed 


\section{Collaborativedepartment/ Unit: The Police,}

\section{Case WLC/CAS/122}

The client, K, came to the clinic for legal assistance so that her husband can take parental responsibility and support in taking care of the children and for the WLC to intervene in the constant beating by her husband. The WLC was of the opinion that $\mathrm{K}$ had to be moved immediately from the home while the case was being looked into. Efforts to get her father to accommodate her proved abortive. Arrangements were made by the WLC for K and her husband to see a psychologist but they were not willing to submit themselves for counselling session. While the case was on-going, $\mathrm{K}$ suffered a psychiatric break down and had to be admitted at a teaching hospital. The WLC was later informed that the issue has been settled amicably.

\section{Collaborativedepartment/ Unit: Department Of Psychology}

\section{Special Case}

This special case was reported to the Clinic by the Director. The case was that of a student of the University with hearing impediment. This was affecting her studies. The client was interviewed with the assistance of an interpreter and the issue was referred to the Special Education Department for urgent intervention.

\section{Collaborativedepartment/ Unit: Department Of Special Education}

\section{Classified Case}

This classified case of an abandoned baby girl was referred to the WLC by the University Health Services (Jaja Clinic). The WLC initially worked with the Campus Security Services and the Police. The case is presently being handled by the WLC, Jaja Clinic, the University Social Welfare unit, the State Social Welfare Unit and the State Juvenile Court.

\section{Collaborative Units: The Campus Security Unit, The Police, University Health Services (Jaja Clinic), University Social Welfare Office,State Social Welfare office and the Juvenile Court.}

\section{Benefits Of The Collaborative Model Of The WLC}

The traditional legal education does not provide the training needed to solve non-legal issues. However with the introduction of clinical legal education and the involvement of students in the clinic, coupled with the fact that non-legal issues come up and are referred to the appropriate collaborating units, law students become more creative problem solvers in law practice. A student clinician in the WLC stated, "I am becoming more confident in handling cases of clients. It is not only the case brought by the client that a clinician will have to deal with. Other issues come up and if they are not addressed, the legal issue cannot be appropriately resolved. Referring non-legal issues to the appropriate units heals the client" 
Another benefit of the collaboration of the WLC with other disciplines is that it brings to reality the multidimensional angle of some cases, therefore letting the student clinician experience what legal practice will be. It therefore prepares a student for practice. A graduate student who spent a year in the WLC had this to say. "I realized that some of the cases I handled in the clinic where not strictly on legal issues. The purported legal issues at times arose out of non legal issues. The clinic was just the first point of call. What I did in most cases was to calm the client down, give a good listening ear, counsel, handle the legal issue, and refer to the appropriate discipline or unit like the social welfare unit. Now that I am in practice, I take the cases of clients from a holistic perspective and advise them accordingly. While I handle the legal issues, I advise as to other experts that may be called in and be involved in the case"

Gross and Filante stated that the clients are the greatest beneficiaries when clinics collaborate with other disciplines. ${ }^{26}$ The authors of this paper agree with this statement. As a result of the collaboration model adopted in the WLC, clients in the clinic have the benefit of free legal services and those with non-legal issues have been able to resolve them free. Mrs A, a client in the WLC had this to say. "I came to the clinic because I wanted the clinic to tell my husband who had abandoned me and the children, to be giving me money to take care of me and the children. I was not well and unhappy when I came to the clinic and I thought the money will remove all these problems. At the clinic, the man listened to me very well and asked me what I wanted. He assured me that the clinic will assist me. He told me that I will have to see someone, who is not a lawyer, and who is not in the clinic, who will not take money from me, who will talk to me because I was unhappy and not well and that because my children are involved, the clinic will have to contact the state social welfare department. My husband is now paying some money to take care of me and the children and I collect this weekly from the clinic. They talked to me at the place where I was told to go and I am now well and happy" In this case, the Psychology Department and the Social Welfare Unit were involved in resolving the case.

Another benefit of the collaborative model adopted by the WLC is that it exposes law students to non legal problems arising from legal problems. The effect is that the students are able to appreciate the importance of other disciplines.

Arising from the above benefit is the fact that law students interact with students and experts in other disciplines. As seen in the case studies above, the clinicians from the WLC in certain instances accompany clients whose cases are referred to other collaborating disciplines and also do some follow up with clients in these places. Through this, law clinicians have an insight into the work done in other disciplines. The collaboration has made law clinicians move out of their legal confine and boundaries. A few law graduates who worked in the WLC enrolled for postgraduate courses in other disciplines. The interest to take the courses was as a result of the experience with clients in the WLC.

The interaction referred to above has mutual benefits to all the collaborating disciplines. A final student from the Department of Guidance and Counselling in the University of Ibadanwas an intern in the WLC for three (3) months. In an interview with her, she had this to say on the collaborative model adopted by the WLC. "There is no one way solution to a problem. A problem should be

26 Gross, J. I and Filante, R. W (2005) Developing a law / Business Collaboration through Pace's Securities Arbitration Clinic in Fordham Journal of Corporate and Financial Law volume 11 2005-2006 at http://ssm.com/ abstract $=1032301$ Retrieved on 12 June 2012 
tackled from all aspects." She further stated "from my training in guidance and counselling, I have come to realize that everyone can guide but not everyone is trained to counsel. In my department, there are different areas of specialization just like in law. I like the referral method adopted by the WLC. It allows the client referred from the WLC to the collaborating discipline/unit to have the benefit of having a number of specialist attention needed to resolve her problem"

There are cases where the issue that triggered off the legal issue was a non legal one. Collaborating with such discipline/unit will be of tremendous benefit in resolving thelegal issue.

\section{Challenges}

The collaborative model adopted by the WLC, which is interdisciplinary or multidisciplinary in approach, has some challenges. These include

\section{Wide Scope}

The scope of the collaboration model adopted by the WLC is too wide. This has brought the clinic into working contact with quite a large number of disciplines.

\section{Inadequate Monitoring/Follow up/ Feedback}

The effect of the wide scope is that clinicians in some cases are unable to properly follow up clients who are referred to other disciplines and unable to have feedbacks which is an important aspect of collaboration

\section{Differences in Goals and Ethical Norms.}

The goals of the WLC and the ethical norms of the legal profession and that of other disciplines/ units sometimes differ. While a goal of the WLC is to provide free legal access to justice for indigent women, some of the collaborating disciplines do not have the same goal. While clients in the WLC are attended to free, they are at times required to pay a token amount in the department referred to. The authors of this paper therefore agree with Connolly (2003) when he stated that some of the barriers to collaboration include cost logistics, and different ethical norms between disciplines. ${ }^{27}$ An example was the case of a client who was physically assaulted by her husband and had to come to the clinic. The clinic referred the case to the police station. At the station, the male officer who attended to the case quietly advised the client to go back home and resolve the issue amicably to the dismay of the clinician and client. It took the intervention of the clinician at the station for the police to take action. The fact was that while the police viewed the matter from a cultural perspective, the WLC took a legal stand.

27 Connolly Kim D (2003) Elucidating the Elephant: Interdisciplinary Law School Classes 11 WASH U Journal of Law and Policy 11 at 18 . 


\section{Geographical proximity/logistic complications}

The fact that the clients are referred to other departments which are not within the WLC has its challenges. The geographical proximity poses a problem for some indigent clients who are unable to afford the cost of transportation. This at times causes problems in keeping up with appointments. Logistic complication has been identified as a major problem. ${ }^{28}$

\section{Conclusion}

The whole world is gradually becoming a global village thus there is a paradigm shift of individuality in solving developmental issues to combination of efforts.

Governments of different countries are not left out in the campaign for collaboration to move their countries forward and internationally relevant. For research, the focus is gradually shifting from personal research to joint research in form of collaboration.

An African proverb says "two heads are better one". In complementing this proverb, researchers are coming together to have comprehensive results. In a bid to be relevant to the immediate community of the University of Ibadan and in furtherance of the internalization policy of the university, the Women's Law Clinic has adopted a collaborative approach in resolving issues. This has been evidenced in the best practice that has been achieved so far whilst more will be done in the nearest future.

In order to deal with the challenges posed by the complex problems faced with globalization, lawyers are joining with other disciplines in problem-solving collaborations. ${ }^{29}$ Collaboration is always the next stage when a person is confused and solution seems not to be in sight. Collaborations is done to exchange ideas and information and to source for information on the way out. In order to achieve the laudable aims and objectives of legal clinics, collaborative ventures are inevitable.

28 Schlossberg D (2003) An Examination of Transactional Law Clinics and Interdisciplinary Education 11 WASHU Law Journal and Policy 195 at 212 - 214 (2003)

29 Minow Martha (2003) Public and Private Partnerships: Accounting for the new religion. 116 Harvard Law Review 1229 
